\title{
PENERAPAN KANCING GEMERINCING DALAM MENINGKATKAN TEAMWORK SKILL PADA MAHASISWA PGSD FKIP UMSU
}

\author{
OLEH : \\ CHAIRUNNISA AMELIA ${ }^{1}$, INDAH PRATIWI ${ }^{2}$ \\ (UNIVERSITAS MUHAMMADIYAH SUMATERA UTARA ${ }^{\mathbf{1 , 2}}$ )
}

\begin{abstract}
This study aims to determine the ability of students to work together in groups or teamwork skills, and to determine student responses in learning in social studies courses using the jingle learning model which is expected from the application of jingle learning model can be seen an increase in learning outcomes student in class. The method used in data collection is documentation, observation and test giving to students. In this research, it can be seen that there is an increase in the ability to work together with students in groups, which in the future will function for students to continue solidarity within groups in other subjects. In learning that uses a different learning model results in the ability of students when understanding a material compared to not using a classical learning or learning model. This can be seen from the average student learning outcomes before using the learning model and by not implementing teamwork skills only 65.2 and learning outcomes using the jingle learning model by applying teamwork skills 93.5. The results obtained can be seen the use of learning models can improve team work skills in PGSD students.
\end{abstract}

Keywords : The learning model of clanking buttons, the ability of teamwork skills in students, and learning outcomes.

\section{PENDAHULUAN}

\section{Latar Belakang}

Pendidikan merupakan salah satu aspek penting yang dianggap sangat menentukan tingkat kemampuan seseorang dalam menghadapi kehidupan. Melalui pendidikan yang cukup, kita dapat hidup sesuai dengan kondisi yang diharapkan. Pendidikan juga merupakan bentuk perwujudan kebudayaan manusia yang dinamis dan sarat perkembangan. Maka oleh sebab itu perkembangan pendidikan harus sejalan dengan perubahan budaya kehidupan. Perubahan dapat dimaknai sebagai perbaikan sebagai antisipasi kepentingan pada masa depan, 
tidak terkecuali pada bidang pendidikan khususnya Pendidikan Guru Sekolah Dasar.

Pendidikan Ilmu Pengetahuan Sosial (IPS) merupakan bagian dari sistem pendidikan nasional. IPS merupakan mata pelajaran yang mengkaji seperangkat peristiwa, fakta, konsep dan generalisasi yang berkaitan dengan isu global. Pembelajaran IPS bukan hanya sebatas pada upaya untuk mentransfer konsep dari dosen kepada mahasiswa yang bersifat hafalan belaka, tetapi lebih menekankan pada upaya agar mereka mampu menjadikan apa yang telah mereka pelajari sebagai bekal dalam memahami dan menjalani kehidupan bermasyarakat di lingkungan yang dinamis, sehingga mereka mampu menjadi warga Indonesia yang demokratis dan bertanggungjawab. Namun faktanya, saat ini motivasi dan hasil belajar siswa terhadap mata pelajaran IPS cenderung rendah. Hal ini diakibatkan persepsi negatif mahasiswa terhadap mata pelajaran IPS. Proses pembelajaran dewasa ini yang sering dipakai yaitu memusatkan pada dosen (pendidik) daripada memusatkan pada mahasiswa atau peserta didik, sehingga hal ini mengakibatkan alasan sebuah materi pembelajaran menjadi membosankan dan dianggap tidak menarik. Hal tersebut juga membuat peran mahasiswa sangat minim, sebaliknya apabila mahasiswa dilibatkan secara lebih aktif didalam proses pembelajaran maka prestasi dalam diri mereka untuk sebuah materi pembelajaran dapat berhasil.

Berdasarkan observasi peneliti terhadap proses belajar mengajar pada mahasiswa, terdapat beberapa kendala yang dihadapi dalam proses pembelajaran IPS, antara lain strategi dan model pembelajaran yang digunakan hanya sebatas diskusi dan banyak mahasiswa yang tidak memperhatikan ketika dosen 
menjelaskan. Melalui kondisi pembelajaran yang demikian, maka perlu diadakan upaya untuk memperbaikinya agar proses pembelajaran lebih menyenangkan dan hasil belajar dapat ditingkatkan, hal ini nantinya diharapkan akan meningkatkan mutu pembelajaran IPS. Salah satu solusi yang ditawarkan untuk mengatasi masalah tersebut yaitu dengan penerapan pembelajaran yang aktif, inovatif, kreatif, dan menyenangkan. guru hendaknya lebih memberikan ruang berpikir dan mengutamakan keaktifan mahasiswa dalam proses pembelajaran. Dengan memberikan ruang berpikir yang cukup, maka siswa akan lebih leluasa untuk menggali dan mengembangkan gagasan yang turut mendukung pengembangan potensi dirinya. Melalui keaktifan mahasiswa akan lebih mudah untuk memahami materi, karena mereka mengalami, menghayati dan mengambil pelajaran dari pengalamannya, serta rasa percaya diri mahasiswa akan terbangun. Salah satu model pembelajaran yang menuntut keaktifan mahasiswa adalah kancing gemerincing.Kancing gemerincingadalah model pembelajaran yang melatih kerjasama, komunikasi dan memberi kesempatan untuk berpendapat dalam kerja kelompok. model ini diharapkan dapat menciptakan suasana belajar yang aktif dengan motivasi belajar mahasiswa yang tinggi.

\section{Rumusan Masalah}

Rumusan masalah dalam penelitian ini adalah"Bagaimana Penerapan Kancing Gemerincing dapat Meningkatkan Teamwork Skill Pada Mahasiswa Semester 2C PGSD FKIP UMSU?”. 


\section{Tujuan Penelitian}

Adapun tujuan penelitian ini adalah untuk meningkatkan Teamwork skill pada Mahasiswa menggunakan model pembelajaran kooperatif kancing gemerincing matakuliah pendidikan IPS pada mahasiswa semester 2C PGSD.

\section{METODE PENELITIAN}

Penelitian ini dilakukan di Universitas Muhammadiyah Sumatera Utara yang berada di jalan Kapten Muchtar Basri No.3 Medan. Penelitian ini dilakukan dengan menggunakan metode Penelitian Tindakan Kelas, untuk melihat peningkatan pembelajaran pada mahasiswa.

Prosedur penelitian yang digunakan adalah yaitu mengetahui permasalahan yang terjadi pada mahasiswa di kelas dengan melakukan tes awal, berikutnya adalah tahapan perencanaan, tahapan pelaksanaan tindakan, melaksanakan observasi dan adanya refleksi.

Teknik pengumpulan data yang digunakan dalam penelitian ini adalah dengan dokumentasi. Dokumentasi, untuk memperoleh informasi yang berkaitan dengan media gambar pembelajaran IPS dan model kancing gemerincing. Setelah itu melakukan observasi (pengamatan) untuk memperoleh informasi yang berkaitan dengan kualitas pelaksanaan KBM. Dan tahapan yang terakhir adalah melakukan tes untuk memperoleh informasi tentang sejauh mana peningkatan pemahaman mahasiswa terhadap materi yang terdapat dalam mata kuliah IPS dengan penggunaan Media gambar Pembelajaran IPS dan model pembelajaran kancing gemerincing. 
Teknik analisa datadengan melakukan reduksi data yang merupakan proses menyeleksi, menentukan fokus, menyederhanakan, meringkas dan mengubah bentuk data mentah yang ada dalam catatan lapangan. Dalam proses ini dilakukan penajaman, pemfokusan, penyisihan data yang kurang bermakna dan menatanya sedemikian rupa sehingga kesimpulan akhir dapat ditarik dan diverifikasi.

Setelah direduksi data siap dipaparkan, artinya tahap analisis sampai pada pemaparan data.Data yang diperoleh dari tes awal dan tes akhir diolah untuk mengetahui skor yang diperoleh siswa, sehingga diketahui Persentase Perolehan Hasil (PPH) per mahasiswa. Untuk Persentase Perolehan Hasil (PPH) dari tes kemampuan memecahkan masalah mahasiswa digunakan rumus sebagai berikut:

$$
\mathrm{PPH}=\frac{\text { skor yang diperoleh siswa }}{\text { skor maksimum }} \times 100 \% \quad \text { (Sutomo, 1985) }
$$

\section{Kriteria:}

$0 \% \leq \mathrm{PPH}<65 \% \quad$ siswa belum tuntas belajar $65 \% \leq \mathrm{PPH} \leq 100 \%$ siswa sudah tuntas belajar

Tingkat kemampuan mahasiswa menyelesaikan tes ditentukan dengan kriteria penentuan tingkat penguasaan siswa terhadap materi yang diajarkan sesuai dengan kriteria sebagai berikut:

Konversi yang digunakan dalam mengubah skor mentah menjadi skor standar dengan norma absolut adalah didasarkan atas tingkat penguasaan terhadap bahan yang diberikan. Tingkat penguasaan itu akan tercermin pada tinggi rendahnya skor mentah yang dicapai. 
Adapun pedoman yang digunakan dalam menentukan tingkat penguasaan siswa adalah sebagai berikut:

\section{Skala Lima Norma Absolut}

\begin{tabular}{|c|c|}
\hline Tingkat penguasaan & Kategori \\
\hline $90 \%-100 \%$ & Sangat tinggi \\
\hline $80 \%-89 \%$ & Tinggi \\
\hline $65 \%-79 \%$ & Sedang \\
\hline $55 \%-64 \%$ & Rendah \\
\hline $0 \%-54 \%$ & Sangat rendah \\
\hline
\end{tabular}

Kemudian penentuan ketuntasan belajar mahasiswa secara klasikal dapat ditentukan dengan menggunakan rumus:

$\mathrm{PKK}=\frac{\text { banyak siswa yang } \mathrm{PPH} \geq 65 \%}{\text { banyak subjek penelitian }} \times 100 \%$

Keterangan :

PKK : Persentase Ketuntasan Klasikal

Berdasarkan kriteria ketuntasan belajar, apabila di kelas tersebut telah mencapai $85 \%$ mahasiswa dengan $\mathrm{PPH} \geq 65 \%$, maka ketuntasan belajar secara klasikal telah tercapai.

\section{HASIL PENELITIAN}

Dari hasil penelitian dan data sementara yang diperoleh dari penelitian yang dilakukan pada Mahasiswa PGSD Semester II, penerapan model pembelajaran kancing gemerincing pada mata kuliah pendidikan IPS membawa peningkatan terhadap Teamwork Skill siswa, hal ini dapat terlihat dari persentase kerja sama tim dan hasil belajar pada saat mengerjakan soal yang berkaitan dengan model pembelajaran kooperatif kancing gemerincing. 
Tabel 1. Data Teamwork Skill Mahasiswa PGSD Semester II Kelas C

\begin{tabular}{|c|c|c|c|c|c|}
\hline \multirow{2}{*}{ No. } & $\begin{array}{c}\text { Rentang } \\
\text { Nilai }\end{array}$ & \multicolumn{2}{|c|}{$\begin{array}{c}\text { Tidak Menggunakan Model } \\
\text { Pembelajaran Kancing } \\
\text { Gemerincing }\end{array}$} & \multicolumn{2}{|c|}{$\begin{array}{c}\text { Menggunakan Model } \\
\text { Pembelajaran Kancing } \\
\text { Gemerincing }\end{array}$} \\
\cline { 3 - 6 } & & Jumlah & $\begin{array}{c}\text { Persentase } \\
(\%)\end{array}$ & Jumlah & $\begin{array}{c}\text { Persentase } \\
(\%)\end{array}$ \\
\hline 1. & $8-12$ & 6 & $21.4 \%$ & - & - \\
\hline 2. & $13-17$ & 16 & $57.2 \%$ & 1 & $3.5 \%$ \\
\hline 3. & $18-22$ & 4 & $14.3 \%$ & 16 & $57.2 \%$ \\
\hline 4. & $23-27$ & 2 & $7.1 \%$ & 11 & $39.3 \%$ \\
\hline
\end{tabular}

Dari data Teamwork Skill mahasiswa yang diperoleh, maka diperoleh nilai hasil belajar mahasiswa yang memperoleh nilai 65.2 dari 35 mahasiswa sebelum pembelajaran menggunakan model pembelajaran kancing gemerincing. Sedangkan, setelah mahasiswa mengikuti pembelajaran menggunakan model pembelajaran kancing gemerincing maka diperoleh nilai 93.5, perolehan nilai ini terjadi karena mahasiswa telah menggunakan model pembelajaran kancing gemerincing pada mata kuliah pendidikan IPS materi peninggalan kerajaan Hindu-Buddha di Indonesia yang telah dikerjakan didalam kelompok. Sehingga nilai yang diperoleh dari analisa data tersebut dapat terlihat bahwa kemampuan mahasiswa bekerja sama didalam tim atau disebut dengan Teamwork Skill mahasiswa dapat terlaksana dengan baik dengan menggunakan model pembelajaran, dalam hal ini tidak berarti dalam setiap diskusi yang dilakukan mahasiswa selama ini tidak menimbulkan rasa kerjasama tim, tetapi dengan dibuatnya variasi model pembelajaran kooperatif dalam proses pembelajaran kita dapat melihat sejauh mana mahasiswa mengerti materi yang didiskusikan didalam kelompoknya dan juga dapat dipakai sebagai cara mahasiswa untuk mengenalkan 
kepada siswa cara pembelajaran yang menarik menggunakan model pembelajaran kooperatif tipe kancing gemerincing.

\section{PENUTUP}

\section{Kesimpulan}

Berdasarkan hasil penelitian yang diperoleh dengan menggunakan media pembelajaran untuk meningkatkan Teamwork Skill mahasiswa, maka diperoleh peningkatan kerjasama tim mahasiswa dan juga meningkatkan hasil belajar mahasiswa. Dengan adanya penggunaan model pembelajaran kancing gemerincing pada mata kuliah pendidikan IPS diharapkan mahasiswa dapat memotivasi dirinya untuk menjadi guru yang lebih kreatif.

\section{Saran}

Setelah penelitian ini selesai diharapkan mahasiswa agar selalu mengulangi kembali dan fokus secara baik pada mata kuliah yang diajarkan khususnya mata kuliah IPS yang setiap semester ada dalam mata kuliah mahasiswa PGSD. Hal ini diharapkan agar mahasiswa memiliki keterampilan bekerja sama dalam tim.

\section{DAFTAR PUSTAKA}

Arikunto, Suharsimi, Suhardjono, Supardi, 2010, Penelitian Tindakan Kelas, Jakarta, Bumi Aksara.

Arikunto, Suharsimi, 2006, Prosedur Penelitian, Suatu Pendekatan Praktik, Jakarta, Rineka Cipta.

Aqip Zainal, 2009, Penelitian Tindakan Kelas, Bandung, Yrama Widya.

Budiningsih, Asri, 2006, Belajar dan Pembelajaran, Jakarta, Rineka Cipta. 
Dimyati \& Mudjiono, 2006, Belajar dan Pembelajaran, Jakarta, Rineka Cipta

Handoyo, Budi dkk, 2003, Pendidikan Ilmu Pengetahuan Sosial SD Terpadu, Malang, Geografi Spektrum Press.

Iman Sukiman, 1999, Mengajar Ilmu Pengetahuan Sosial (IPS) di SD, Bandung, Depdikbud Propinsi Jawa Barat.

Isjoni, 2011, Cooperative Learning, Mengembangkan Kemampuan Belajar Berkelompok, Bandung, Alfabeta.

Masnur, Muslich, 2009, Penelitian Tindakan Kelas, Yogyakarta, Bumi Aksara.

Miles, M.B \& Huberman, A.M, 1992, Analisis Data Kualitatif, Jakarta, UI-Press

Moleong, 2006, Metodologi Penelitian Kualitatif, Bandung, Remaja Rosda Karya.

Mulyasa, E, 2006, Kurikulum Yang Disempurnakan, Pengembangan SKKD, Bandung, Remaja Rosda Karya.

Nurkancana, Wayan, 2000, Evaluasi Hasil Belajar, Surabaya, Usaha Nasional.

Rusman, 2011, Model-model Pembelajaran, Mengembangkan Profesionalisme Guru, Jakarta, Raja Grasindo Persada.

Solihatin, Etin, Raharjo, 2011, Cooperative Learning, Analisis Model Pembelajaran IPS, Jakarta, Bumi Aksara.

Sunarso dan Anis Kusuma, 2008, Ilmu Pengetahuan Sosial Untuk SD dan MI Kelas III, Pusat Perbukuan Departemen Pendidikan Nasional.

Sardjiyo dkk, 2008, Pendidikan IPS di SD, Jakarta, Universitas Terbuka.

Sakdiyah, Siti Halimatus, 2010, Bahan Ajar Pembelajaran IPS SD, Universitas Kanjuruhan Malang.

Trianto, 2007, Pembelajaran Model-model Inovatif Berorientasi Konstruktivistik, Jakarta, Prestasi Pustaka Publisher.

Tantya Hisnu, Winardi, 2008, , Ilmu Pengetahuan Sosial Untuk SD dan MI Kelas $I V$, Pusat Perbukuan Departemen Pendidikan Nasional. 
Undang-undang No. 14 Tahun 2005 tentang Guru dan Dosen.

Undang-undang No. 20 Tahun 2003 tentang Sistem Pendidikan Nasional.

Winataputra, S, Udin dkk, 2007, Materi dan Pembelajaran IPS SD, Jakarta, Universitas Terbuka.

Wardahani, IGAK dkk, 2004, Penelitian Tindakan Kelas, Jakarta, Departemen Pendidikan Nasional, Jakarta.

Wahab, Abdul aziz, 2009, Metode dan Model-model Mengajar IPS, Bandung, Alfabeta. 